\title{
Yoga Asanas for Backache
}

\author{
Priyadarshini Tewari* \\ Department of Vikriti Vigyan, India
}

Submission: February 27 ,2019; Published: April 12, 2019

*Corresponding author: Priyadarshini Tewari, Department of Vikriti Vigyan, BHU, India

\begin{abstract}
Yoga is derived from Sanskrit root 'YUJA' meaning of which is to 'UNITE' or integrate. This means the union of individual consciousness (Atma) with the divine/supreme consciousness (Parmatma). Patanjali has stated 'Yoga Chita Vritti Nirodha' the state of Control over mind. Patanjali has considered 'Astanga-Yoga' or eight-fold yoga, Yama, Niyam, Asanas, Pranayama, Pratyahara, Dharana, Dhyana and Samadhi. Yama, Niyam, Asana, Pranayama and Pratyahara is 'Bahirangayoga' and Dharana, Dhyan and Samadhi are considered as 'Antaranga yoga'. Yama and Niyam are the ethical practices, Asanas is physical control over body postures, Pranayama is control over breath. Pratyahara is essentially the sensorial practice of Yoga i.e. to withdraw the mind from the senses, it acts as bridge between Bahiranga yoga and Antaranga yoga. Dharana, Dhyan and Samadhi are the spiritual practices. Maintaining of physical health and prevention or cure of diseases is not the objective of yoga, but nowadays it is being proved scientifically that Yogaasanas help in maintaining physical health also.
\end{abstract}

\section{स्थिरंसुखमासनम्।। पातंजल योग सूत्र 2/46}

Asana (Sanskrit: आसन āsana 'sitting down'), is a posture in which an individual may stay stable and comfortable for long period.

\section{प्रयत्नशैथिल्यानन्तसमापत्तिभ्याम् ।। योग सूत्र 2/47}

In Yoga Darshan Patanjali has stated that an Asana is achieved by stopping all kinds of physical attempts and activities after sitting in stable and comfortable posture.

Keywords: Asana; Astanga Yoga; VrittiNirodha; Bahiranga yoga; Antaranga yoga; Darshan Patanjali; Samadhi; Dharana; Pratyahara

\section{Introduction}

Back pain is a common complain faced by most of the people during life time. It feels like an ache, tension or stiffness / soreness in back which can be triggered by bad posture while sitting or standing, bending awkwardly, or lifting weight incorrectly. In many patients, it is not due to a serious disease and the exact cause is not identified then it is termed as nonspecific lower back pain. The patients are advised to keep themselves active and mobile; some patients may get relief by pain killers. Many patients may get relief within 6 weeks, but it may recur from time to time. Some cases may develop chronic (persistent) pain and may need further treatment for that.

\section{Anatomy of the low back}

The spinal column is made up of circular bones called 'vertebrae' and between each vertebra is a disc made up of a strong fibrous outer layer and a softer, gel-like centre. The discs act as shock absorbers and allow the flexibility of spinal column. The structures in lumbar area which may be responsible for low back pain are lumbar vertebra, vertebral discs, ligaments around the spine and discs, spinal cord and nerves, muscles of the low back, internal organs of the pelvis and abdomen, and the skin covering the lumbar area. The nerves that provide sensation and stimulate the muscles of the low back, the thighs, legs, feet, and toes all come out of the lumbar spinal column through bony openings known as "foramen." The group of muscles that are responsible for flexion, extension and rotation of the back and movement of the lower limbs are attached to the lumbar spine through tendons.

\section{Causes of Back pain}

Some of the common causes of back pain are as follows:

Strain - this is the common cause of back pain: Strained muscles, strained ligaments, lifting weight improperly, and Lifting too heavy weight, an abrupt and awkward movement.

\section{Structural problems}

The following structural problems may also result in back pain:

Ruptured disks: Spinal vertebra are cushioned by disks, if the disk ruptures there will be pressure on a nerve, resulting in back pain. 
Bulging disks: Like the ruptured disks, a bulging disk can result in more pressure on a nerve.

Sciatica: A sharp and shooting pain that travels from hips, down the back of the leg up to the foot caused by a bulging or herniated disc by pressing the nerve.

Arthritis: Patients suffering from osteoarthritis experience pain with the joints of the hips, lower back, knees and hands. In some cases, spinal stenosis can develop the space around the spinal cord narrows, which causes back pain.

Abnormal curvature of the spine: The spinal curves are unusual then the patient is more likely to experience back pain. E.g. scoliosis.

Osteoporosis: Condition in which bones, including the spinal vertebrae, become brittle and porous, and leading to compression fractures.

Bad mattress: If a mattress does not have good support to the body parts and does not keep the spine straight, there is a greater risk of developing back pain.

\section{Everyday Activities or Poor Posture}

Back pain can also be the result of some day today activities or from poor posture. Bending and sitting awkwardly, Pushing, Pulling, Carrying, lifting, standing for long periods, Bending down for long periods, Twisting, Coughing, Sneezing, Muscle tension, Over-stretching, Long driving sessions without a break.

\section{Diagnosing Back Pain}

Most of the physicians will be able to diagnose back pain after carrying out a thorough physical examination and interrogating the patient. If the doctor suspects some deep injury to the back, then various tests may be advised to be done. Also, there is suspicion about the back pain might be due to an underlying cause, or if the pain persists for too long, further investigations may be advised to rule out the pathology. Investigations like X-rays or CT (computerized tomography) or MRI (magnetic resonance imaging) scan may be used to get a better view of the state of the soft tissues of patient's back [1-5].

\section{Treatment for Back Pain}

Back pain needs treatment and prevention for further recurrence. Measures to get relief of back pain are:

a) A back brace to support back

b) Local application of Cold packs and heat therapy or massage

c) Stretching and strengthening exercises like yoga asanas may be helpful

d) Traction (if necessary)

e) Lifestyle change for prevention of back pain. f) Pain killers may be advised by the doctor for pain control.

Yoga Asanas may be helpful in relieving back pain, but before starting consult a physician and a yoga expert for learning various asanas to avoid any complications. Yoga Asanas which help to relive back pain are as follows

\section{Tadasan}

\section{Method}

(Figure 1) First stand straight with feet in contact with each other, inhale and lift heel up and raise both hands together straight up over the head as much as possible and interlock the hands and stretch the palms. Keep for few seconds and relax.

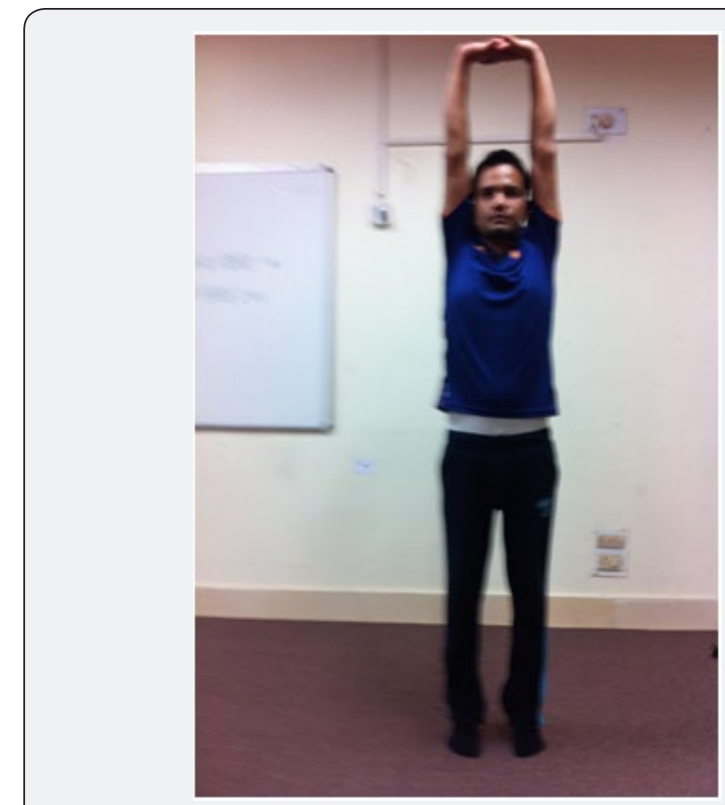

Figure 1: Tadasan

\section{Other benefits of tadasana}

a) Increases strength, power, and mobility in the feet, legs, thigh, back and hips.

b) Tones abdomen and buttocks muscles.

c) Relieves tension, aches, sciatica pain and pain of the body.

d) Encourages healthy digestion and elimination of waste products.

\section{Parsvakonasana}

\section{Method}

(Figure 2) In standing position, take wide stance with arms and legs extended. Turn right foot out at 90 degrees and the left foot in slightly. Bend right knee until thigh bone is parallel to the ground. Place right hand on the floor outside near right foot. Extend left arm over left ear, as shown. Keep for about 60 seconds relax and repeat on other side. 


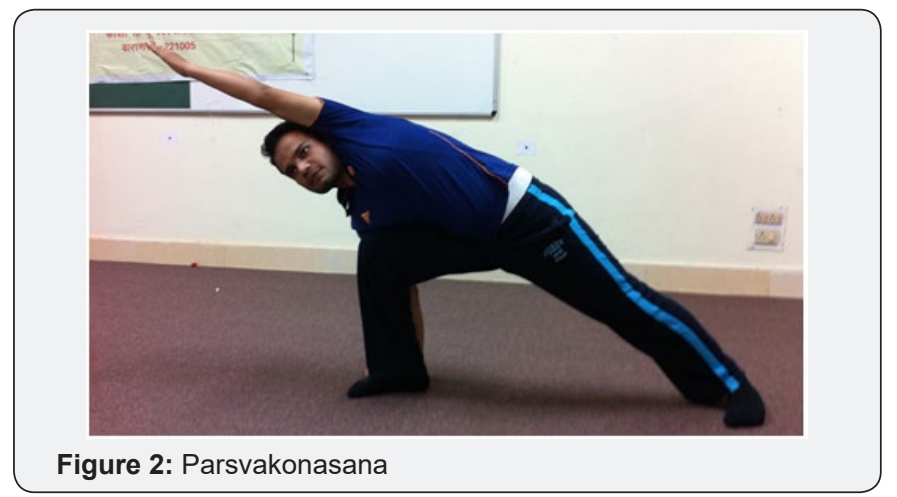

Other benefits of parshvakonasana

a) The spinal muscles are toned up by this posture.

b) It helps to revitalize the whole body. c) This posture improves the blood circulation to the whole body; so long-time sitting profession people are benefitted.

d) Helpful to reduce the fat from the hip region

\section{Marjarasan}

\section{Method}

(Figure 3) Get in hand and knee position with hands lined up beneath the shoulders and knees straight line with hips. Take a deep breath in, and as you inhale bend your spine, and draw the belly toward the floor, head tilted back, and hips toward the sky and tightened.

As you exhale, arch the back and abdomen upward and, curling the chin toward the chest. Repeat these two poses, 8 to 10 times and relax.

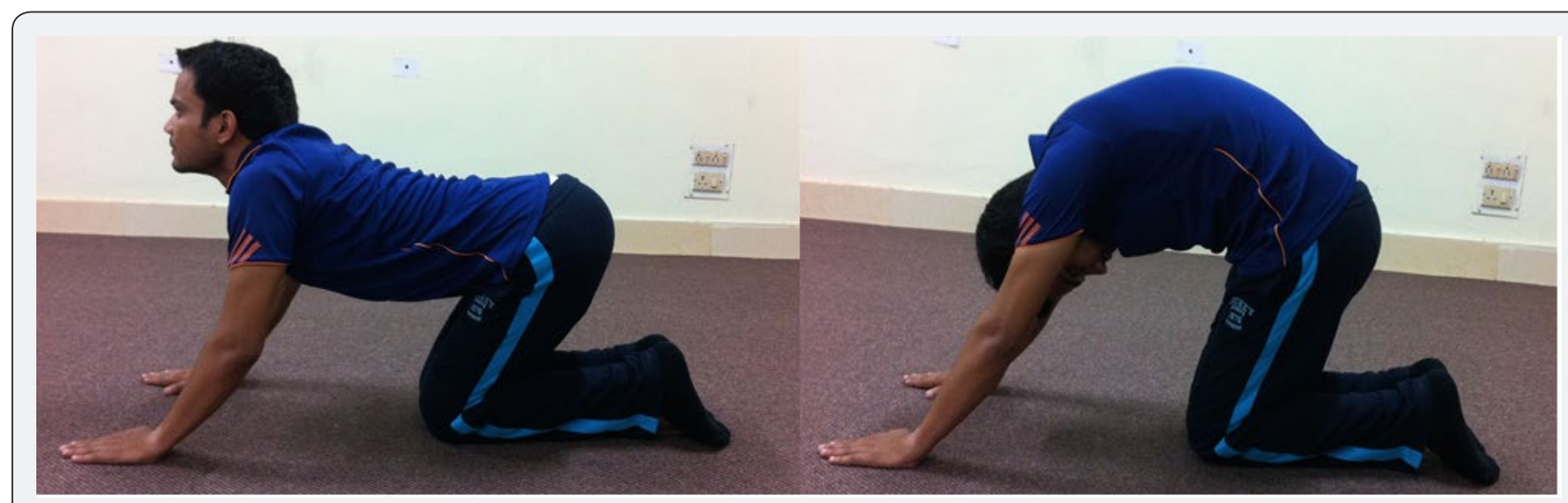

Figure 3: Marjarasan

\section{Other benefits of marjarasan}

a) Increases the mobility of the verterbral column.

b) Relives tension of cervical, thoracic, and lumbar spine.

c) Strengthens and tones the muscles of arms and abdomen.

d) Improves circulation and massages the abdominal organs.

\section{Bhujangasan}

\section{Method}

(Figure 4) Lie on stomach with both hands on either side. Forehead should be touching the ground. Place hands, palms down, next to the chest on side, legs and feet together, body straight, soles upwards. Take a deep breath and lift the upper body, remain for 60 seconds and relax.

\section{Benefits of bhujangasana}

a) Stretches and strengthens muscles of the shoulders, chest and abdomen. b) Removes stiffness of the lower back.

c) Firms and tones the muscles of buttocks.

d) Strengthens the spine.

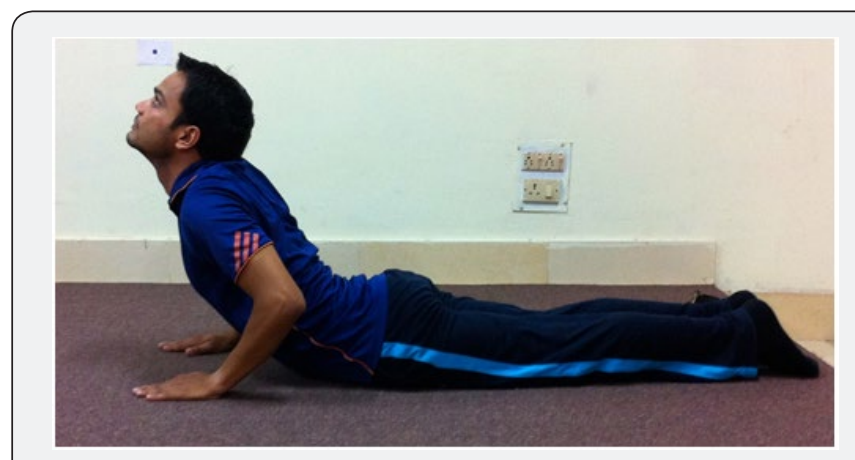

Figure 4: Bhujangasan

\section{Shalabhasan}

Method

(Figure 5) Lie on stomach with legs stretched and hands on either side. The chin should be touching the ground. Place hands, 
with palms facing upwards, below thighs. Now lift both the legs in the air while keeping them straight without bending at knee and hold them there for three-five breaths and relax.

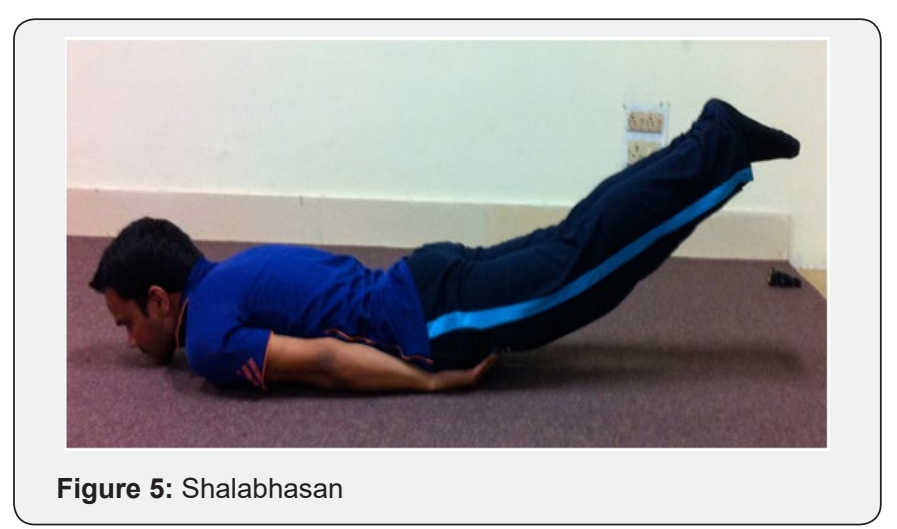

\section{Other benefits of shalabhasana}

a) Relieves arthritis and rheumatism pain.

b) It strengthens the muscles of back, legs, whole body, and abdominal organs.

\section{Purvottanasana}

\section{Method}

(Figure 6) Place hands near the shoulder with fingertips pointing forwards towards the feet. Bend knees and place your feet on the floor hip-width distance apart. On an exhalation, push your hands and feet to lift your hips to the same height as shoulders and straighten arms toes touching the ground, let head hang back behind. Stay here for up to 30 seconds and slowly come down.

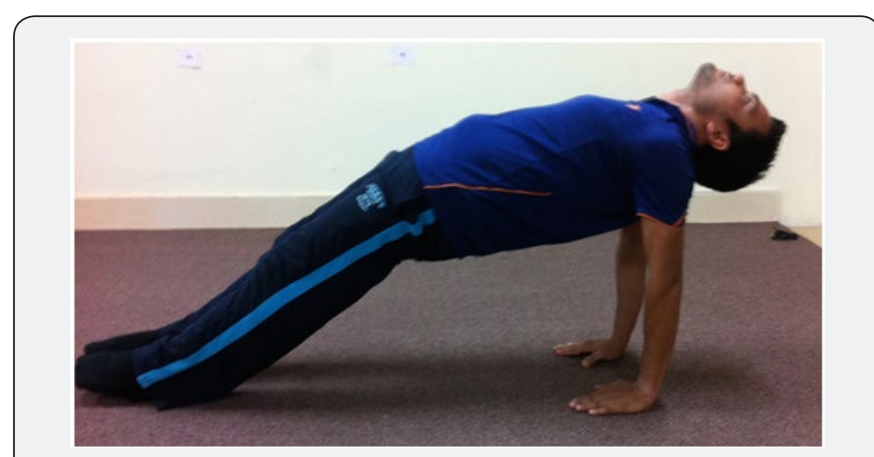

Figure 6: Purvottanasana

\section{Other benefits of purvottanasana}

a) Strengthens the muscles of hands, wrists, back, and legs.

b) Stretches the shoulders, chest, and front of ankles.

\section{Gomukhasana}

\section{Method}

(Figure 7) In sitting posture bend left leg, bring its heel under the right thigh near to right hip, then bend right leg over the left knee and let your right heel come close to left hip. Your right knee should be positioned directly above the left knee. Bring left forearm behind the back, position the back of the left hand in the middle of back, close to shoulder blades. Bending the right elbow, the right palm should face back and the fingers of the right hand should be pointed downward. Clasp the fingers of the left hand with the right hand; pull shoulders away from each other to experience the stretch in the shoulders. Remain in this pose from 10 seconds. Repeat on other side.

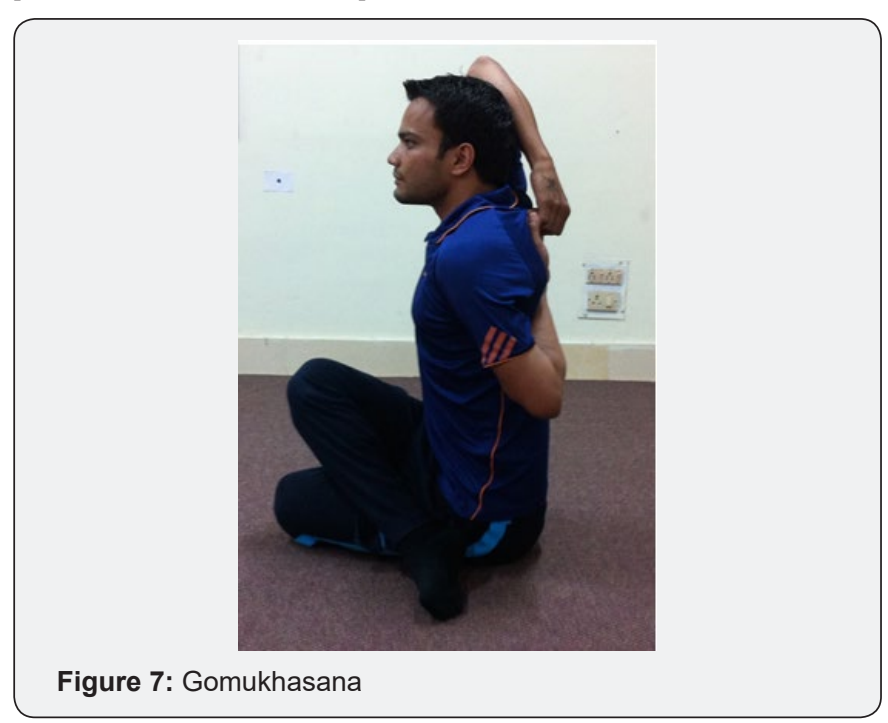

\section{Benefits of gomukhasana}

a) Stretches the muscles and relieves pain of back, hips, thighs, ankles and chest, shoulders and arms.

b) It helps to make the spine straight and improves body posture.

c) It is beneficial in respiratory problems as it gives exercise to the lungs.

\section{Uttkatasana}

\section{Method}

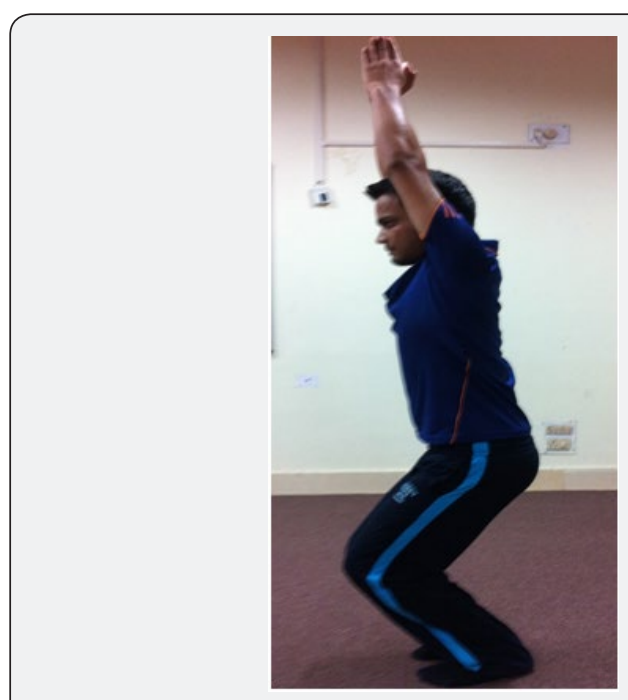

Figure 8: Uttkatasana 
(Figure 8) Stand straight, inhale while stretching arms forwards and up, exhale bending the knees with parallel to the ground, legs and knees together, keep chest, arms back in straight line. Hold for 3-4 breaths and relax, repeat 6-8 times.

\section{Other benefits of uttkatasana}

a) Strengthens ankles, thighs, calves, back, neck and muscles of chest and arms.

b) Helps to get rid of buttock fat.

c) Relieves pain of joints.

\section{Ushtrasana}

\section{Method}

(Figure 9) Sit on knees and bend backwards, hold right heel with right hand and left heel with left hand. Bend head and neck backwards as much as you can and push waist area slightly forward. Breathing should be normal for 6 to 10 seconds in this position. Removes hands from heel and relax.

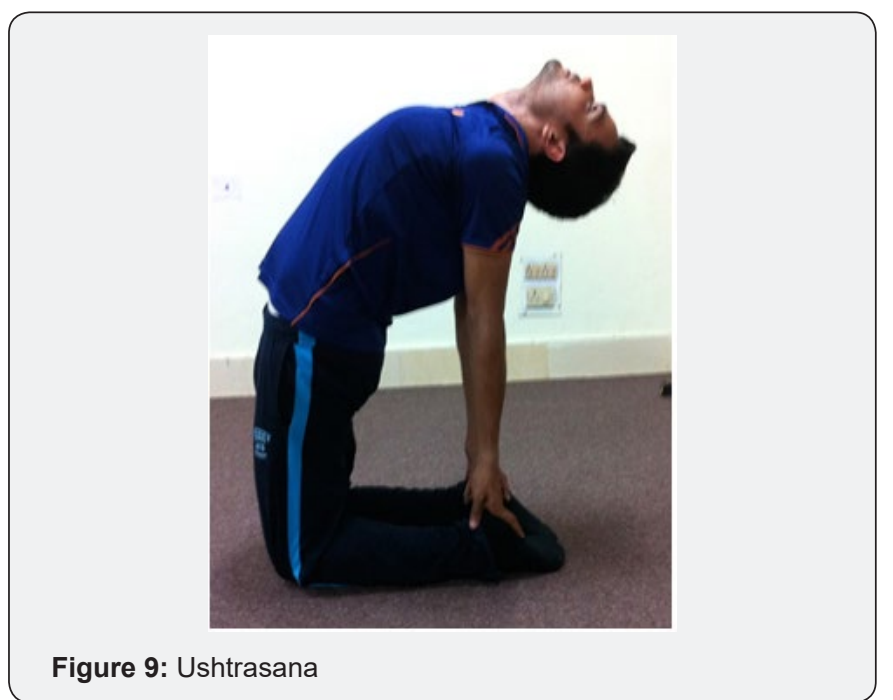

\section{Other benefits of ushtrasana}

a) Helps to improve lung capacity, the muscles of chest, abdomen, and neck and back becomes flexible.

b) Relieves Neck, Shoulders and back pain.

c) Reduce the fats on the stomach, stimulates abdominal organs and improves digestion.

\section{Adhomukha swanasana}

\section{Method}

(Figure 10) From hands and knees position, place hands shoulder distance apart, fingers spread wide, wrist creases parallel with top of mat. Place knees slightly further back than hips. Tuck toes under, and straighten legs, bring heels toward the ground. Press hips back and lift pelvis towards ceiling. Tuck chin slightly to lengthen back of neck. Get into position like shown in photo, keep for 4-5 breaths and relax.

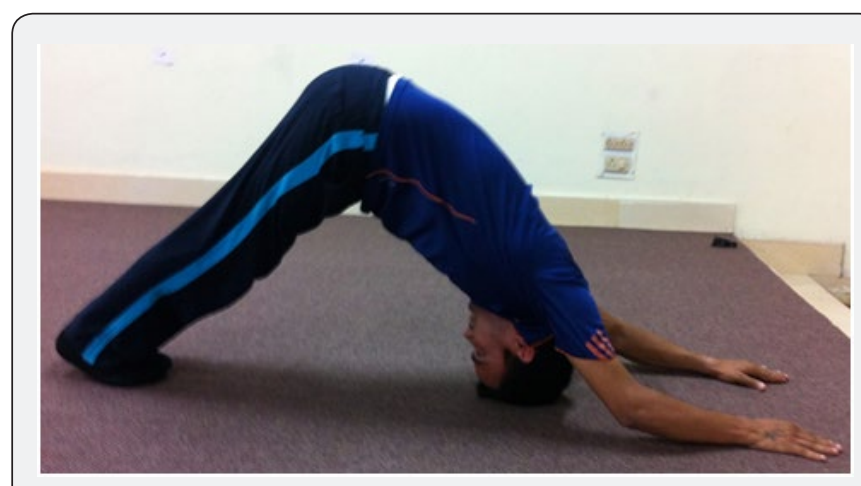

Figure 10: Adhomukha swanasana

\section{Other benefits of adhomukha swanasana}

a) Increased blood flow to the head, shoulder stand can help improve brain function, memory and reduce anxiety and depression.

b) Takes pressure off the heart, which must work less to get blood flowing to the brain.

c) Strengthens and tones the muscles of arms and legs.

d) Helps to relieve pain in the upper, middle and lower back.

\section{Paschimottanasana}

\section{Method}

(Figure 11) Sit with your legs spread out keeping rest of the body straight. Lift your arms overhead until your upper body forms a 90-degree angle with your legs. Keep the body straight and bend forward to catch the toes without bending knees. If this is difficult, bend your knees as much as you need to take the strain out of your back.

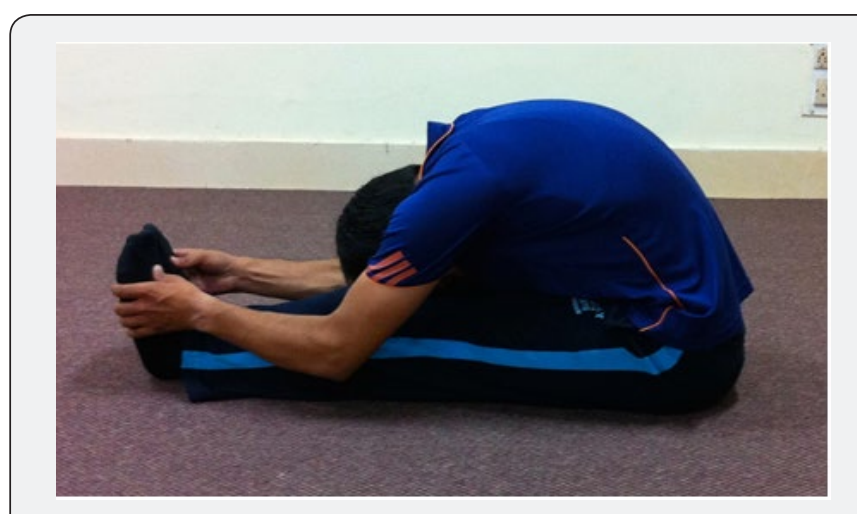

Figure 11: Paschimottanasana

\section{Benefits of paschimottanasana}
a) Reduces fat from the abdomen.
b) Stretches the spinal muscles and brings flexibility.
c) Relieves constipation and digestive disorder.
d) Tones the abdominal pelvic organs. 
e) Balance the menstrual cycles, this asana is recommended especially for women after delivery to tone up the abdominal muscles.

\section{Ardhamatsyendrasana}

\section{Method}

(Figure 12) Sit erect and stretch out both the legs, fold right leg and place the right heel in the perineum. Place the left foot flat on the floor, crossing the right knee. The left heel should rest close to the right side of the right knee. Pass the left arm over the right side of the right knee. Catch the right big toe with the index finger, middle finger and thumb of the left hand. Slide the right hand across the back of right thigh. Turn around your head, neck, shoulders and the whole trunk to the right and bring the chin in line with the right shoulder. Keep the head and spine in erect position, maintain this position until strain is felt relax and repeat on the other side.

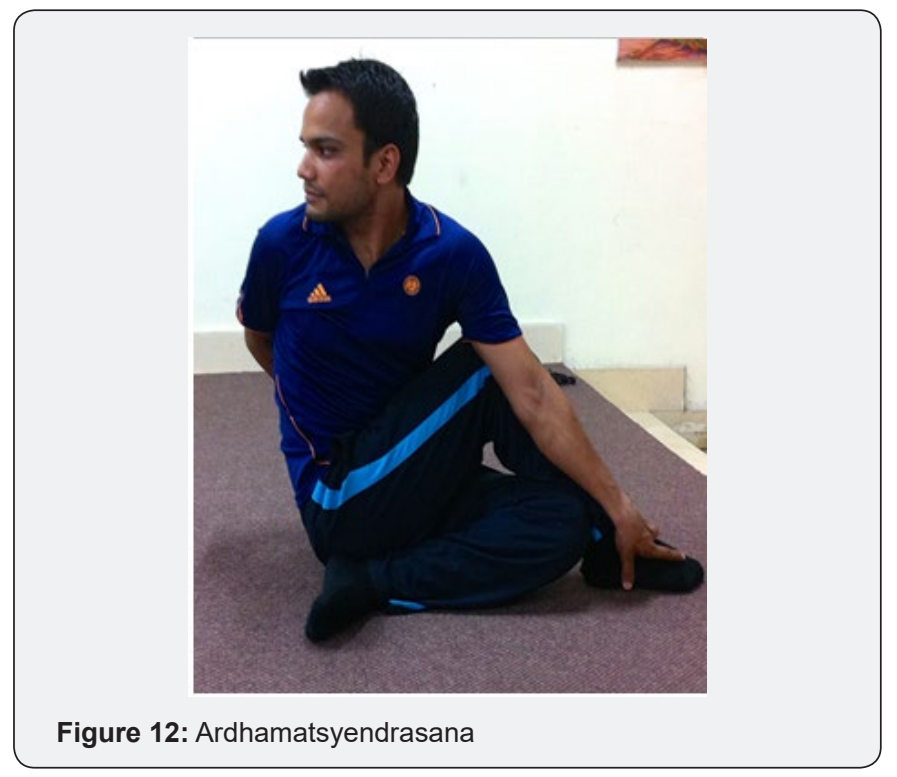

Other benefits of ardhamatsyendrasana

a) This is best of the twisting postures as it rotates the spine around its own axis besides giving two side-twists to the spine throughout its length.

b) Stretches and increases flexibility of the spine, shoulders, neck, and hips

c) Stimulates function of abdominal organs and improves digestion and elimination of wastes

d) Relieves symptoms of backache, fatigue, menstrual discomfort and sciatica pain.

\section{Katichakrasana}

\section{Method}

(Figure 13) Stand straight and keep 1 to $1.5 \mathrm{ft}$ distance between both feet. Now spread both the hands in the line of the shoulders and after that keep left hand on the right shoulder and keep the right hand on the trunk by bringing it from the back side. Keep on breathing normally and bring the face in the line of left shoulder by moving it. Stay in this position for 8-10 breaths and repeat this activity by changing the side and return in normal position.

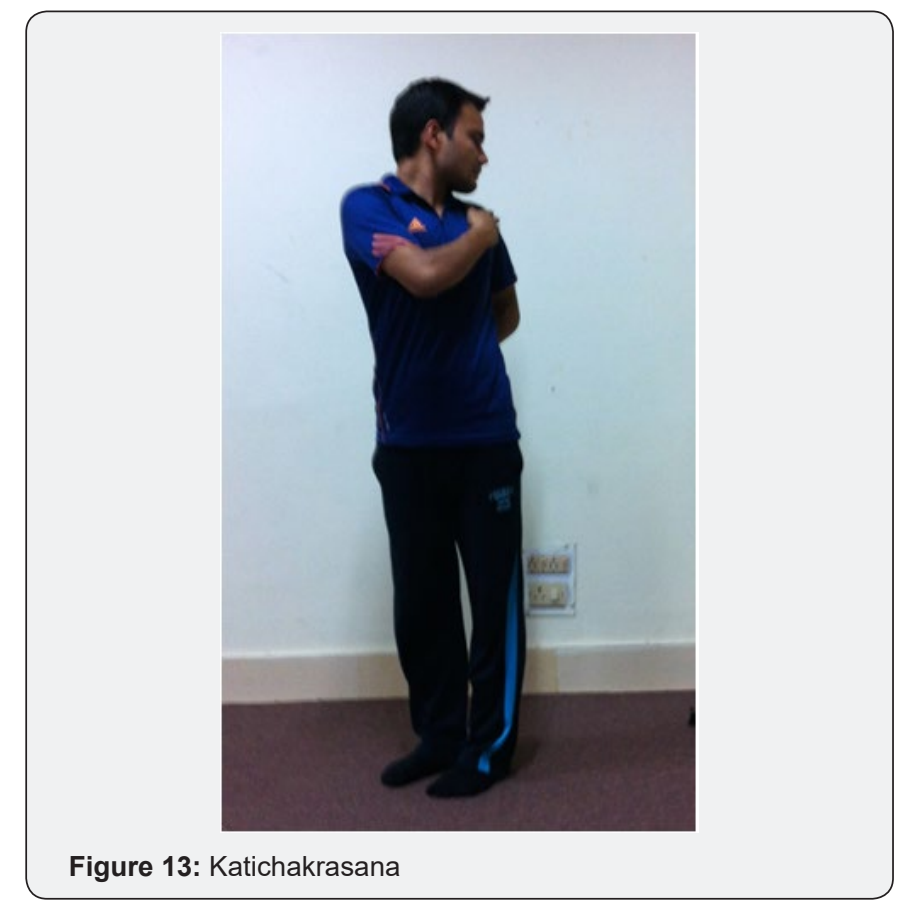

\section{Other benefits of katichakrasana}

a) Improves the flexibility of the neck, back and spinal muscles.

b) Massages the abdominal visceral organs.

c) Makes the waist thin and flexible by decreasing the fat on abdomen.

\section{Conclusion}

Back pain should not be neglected, avoid the work which causes back pain. It should be seriously diagnosed and treated appropriately. The asanas mentioned in this paper are helpful in relieving the back pain along with other benefits also. All these asanas should be done strictly under expert supervision to avoid any complications. If there is no improvement in pain, immediately consult a doctor.

\section{Acknowledgement}

I would like to thanks the faculty and the students of department of Swasthavritta, Faculty of Ayurveda, Institute of Medical Sciences, Banaras Hindu University, for their help.

\section{References}

1. Singh RH, Swasthavritta Vigyan (1999) Chowkhambha Sanskrit Pratisthan.

2. Rao MV (2011) The Essence of Yoga, Chaukhambha Orientalia. $1^{\text {st }}(\mathrm{edn})$, Varanasi, India. 
3. Saraswati SS (2008) Asana Pranayam Mudra Bandha. Yoga Publications Trust, Munger, Bihar, India.

4. Suman KK (2010) Yoga for All. Lotus Press Ltd. Delhi, India.
5. Gore MM (2005) Anatomy \& Physiology of Yogic Practices. New Age Books, Delhi, India.

Your next submission with Juniper Publishers
will reach you the below assets
- Quality Editorial service
- Swift Peer Review
- Reprints availability
- E-prints Service
- Manuscript Podcast for convenient understanding
- Global attainment for your research
- Manuscript accessibility in different formats
( Pdf, E-pub, Full Text, Audio)
- Unceasing customer service
Track the below URL for one-step submission
https://juniperpublishers.com/online-submission.php

This work is licensed under Creative Commons Attribution 4.0 License

DOI: $10.19080 / J Y P .2019 .07 .555708$ 